\title{
Human Adipocyte Glucose Transport System Biochemical and Functional Heterogeneity of Hexose Carriers
}

\author{
Stephan Matthaei, W. Timothy Garvey," Richard Horuk, Thomas P. Hueckstaedt, ${ }^{\star}$ and Jerrold M. Olefsky* \\ *Department of Medicine, University of California, San Diego, La Jolla, California 92093; \\ Veterans Administration Medical Center, Medical Research Service, San Diego, California 92161
}

\begin{abstract}
We have investigated glucose transport proteins in isolated human adipocytes. Using the cytochalasin $B$ binding assay to measure glucose transporters in subcellular membrane subfractions, we found that insulin induced translocation of intracellular glucose transporters to the cell surface. Isoelectric focusing of glucose transporters photolabeled with $\left[{ }^{3} \mathrm{H}\right]$ cytochalasin B revealed two distinct glucose transporter isoforms in low density microsomes focusing at pH 5.6 and pH 6.4, but only the pH 5.6 isoform was detectable in plasma membranes and only the pH 6.4 form was found in the high density microsomes. Insulin recruited only the pH 5.6 glucose transporter from the low density microsomes to the plasma membrane with no effect on the pH 6.4 transporter isoform. The results suggest that the $\mathrm{pH} 6.4$ species is an immature form of the glucose transporter initially located in the high-density microsome fraction, which then migrates to the low-density microsomes where it matures (converted to pH 5.6 species) and becomes available for insulin-mediated recruitment to the plasma membrane.
\end{abstract}

\section{Introduction}

There is a considerable body of evidence that postreceptor defects play an important role in the pathogenesis of the insulin resistance in non-insulin-dependent diabetes mellitus (NIDDM) ${ }^{1}$ and obesity (1-3). Further, studies in adipocytes isolated from these patients show that impaired insulin responsiveness is largely due to defects in the glucose transport system $(4,5)$. However, the cellular and molecular events that accompany these processes are still unknown. Major impediments in this area of research have been the lack of information on the molecular properties and subcellular distribution of the human adipocyte glucose transporter, and how it is influenced by insulin. Recently, Armoni et al. reported data on glucose transporter distribution in human omental adipocytes from normal and obese patients (6). Although these authors provided evidence in support of the no-

Address reprint requests to Dr. Olefsky. Dr. Matthaei's present address is Department of Medicine, University of Hamburg, Universitats Krankenhaus Hamburg-Eppendorf, Federal Republic of Germany. Dr. Horuk's present address is NIEHS, National Institutes of Health, P.O. Box 12233, Research Triangle Park, NC 27709.

Received for publication 21 July 1986

1. Abbreviations used in this paper: HDM, high density microsomes; LDM, low density microsomes; NIDDM, non-insulin-dependent diabetes mellitus; PAGE, polyacrylamide gel electrophoresis; PM, plasma membranes.

J. Clin. Invest.

(c) The American Society for Clinical Investigation, Inc.

0021-9738/87/03/0703/07 \$1.00

Volume 79, March 1987, 703-709 tion that insulin stimulates glucose transport in the human adipocyte via a mechanism similar to that in rat adipocytes; translocation of glucose transporters from an intracellular pool to the plasma membrane $(7,8)$, biochemical events that accompany these processes are still unknown.

We have recently shown that there is heterogeneity of glucose transporter species in the intracellular pool in rat adipocytes and that only one glucose transporter isoform is translocatable by insulin (10). Our current goal was to study in human adipocytes the mechanism by which insulin activates glucose transport at the biochemical level. This is important since characterization of the human adipocyte glucose transport system is a prerequisite to elucidate potential structural and functional defects of the glucose transporter molecule and/or the translocation process in pathophysiologic states $(1-5,9)$. The studies presented here revealed that the biochemical events that accompany insulin activation of glucose transport in human omental adipocytes are similar to those in rat adipocytes and provide further information on the subcellular distribution, and structure of the glucose transporter isoforms.

\section{Methods}

Materials. $\left[{ }^{3} \mathrm{H}\right]$ cytochalasin B $(10-15 \mathrm{Ci} / \mathrm{mmol}$ sp act) and endoglycosidase $F$ were obtained from New England Nuclear, Boston, MA. Carrier ampholytes and all other reagents for isoelectric focusing and electrophoresis were from Bio-Rad Laboratories, Richmond, CA. Grade collagenase (type I) was from Worthington Biochemicals, Inc., Freehold, NJ. Bovine serum albumin (BSA, fraction V) was from Reheis Chemical Co., Berkeley Heights, NJ. Tris and all other reagent grade chemicals were from Sigma Chemical Co., St. Louis, MO.

Methods. Human omental and subcutaneous tissue was obtained from patients undergoing elective abdominal surgery. The patients had normal fasting plasma glucose levels, normal oral glucose tolerance tests, and did not have a family history of diabetes. Approximately 70-140 g of omental and $30-60 \mathrm{~g}$ of subcutaneous tissues were removed from each patient, $\sim 10 \mathrm{~min}$ after the operation began. The adipose tissue was transported to the laboratory in Krebs-Ringer-Hepes-bicarbonate buffer containing 5\% BSA and $5 \mathrm{mM}$ glucose. All procedures were approved by the University of California at San Diego (UCSD) Human Investigation Committee and informed written consent was obtained from each patient.

Isolation of adipocytes and preparation of subcellular membrane fractions. Isolated adipocytes were obtained by collagenase digestion ( 3 $\mathrm{mg} / \mathrm{ml}, 37^{\circ} \mathrm{C}$ for $1 \mathrm{~h}$ ) of omental and subcutaneous adipose tissue as described by Rodbell (11) and modified by Ciaraldi et al. (5). Subcellular fractions from isolated adipocytes were prepared by differential ultracentrifugation as described by Karnieli et al. (12). Membrane proteins were suspended to a final concentration of $1-5 \mathrm{mg} / \mathrm{ml}$ and stored at $-80^{\circ} \mathrm{C}$. Protein was determined by the method of Lowry et al. (13) as modified by Peterson (14). Marker enzyme assays were as previously described (12).

Determination of glucose transporter number. The number of D-glucose inhibitable cytochalasin B binding sites in the subcellular fractions was determined according to the method of Wardzala et al. (15). 
Photochemical crosslinking of membranes and sodium dodecyl sulfatepolyacrylamide gel electrophoresis (SDS-PAGE). Membrane fractions prepared from human adipocytes were resuspended in $50 \mathrm{mM}$ phosphate buffer ( $\mathrm{pH}$ 7.4) to a final concentration of $1-5 \mathrm{mg}$ membrane protein/ ml. After incubation for 10 min at $4^{\circ} \mathrm{C}$ with $\left[{ }^{3} \mathrm{H}\right]$ cytochalasin $\mathrm{B}(5 \mu \mathrm{M})$ and cytochalasin $\mathrm{E}(2 \mu \mathrm{M})$, the membranes were irradiated for 5 min at $4^{\circ} \mathrm{C}$ using a high-intensity ultraviolet-lamp $(253 \mathrm{nM})$. Experiments involving $\mathrm{D}$ - or L-glucose were carried out as described above except that the sugar $(500 \mathrm{mM})$ was incubated with the membranes for $30 \mathrm{~min}$ before the addition of cytochalasin $B$.

Membranes covalently crosslinked to $\left[{ }^{3} \mathrm{H}\right]$ cytochalasin B were solubilized by boiling for $5 \mathrm{~min}$ in Laemmli sample buffer (16), followed by centrifugation and analysis by SDS-PAGE as previously described (10). Proteins corresponding to a molecular mass of 40-55 kD were excised from the slab gels and electrophoretically extracted as described by Hunkapiller et al. (17).

Isoelectric focusing. The extracted and concentrated SDS-solubilized glucose transporter was subjected to isoelectric focusing on cylindrical polyacrylamide gels. Gel composition and isoelectric focusing conditions were as described previously (18). Duplicate gels were run; one was processed for scintillation counting as above, while slices from the other gel were extracted for $1 \mathrm{~h}$ in $1 \mathrm{ml}$ of water (four slices per tube) and the $\mathrm{pH}$ determined (16)

Immunological identification of the glucose transporter. Aliquots of the membrane subfractions isolated from human omental adipocytes were taken up in a Laemmli sample buffer and analyzed by SDS-PAGE on 1.5 -mm slab gels containing $9 \%$ polyacrylamide resolving gel. The gels were run at $40 \mathrm{~mA}$ for $2.5 \mathrm{~h}$. The proteins were transferred to nitrocellulose paper as described by Towbin et al. (19), and reacted with an antiserum against the purified human erythrocyte glucose transporter. Crossreacting protein was visualized using ${ }^{125} \mathrm{I}$-protein $\mathrm{A}$ according to the method of Wheeler et al. (20). Autoradiography was carried out at $-80^{\circ} \mathrm{C}$ using Kodak XARS film and a lighting-plus intensifying screen (Cronex, E. I. Dupont de Nemours, Inc., Wilmington, DE).

Endoglycosidase $F$ treatment of membranes. $\left[{ }^{3} \mathrm{H}\right]$ Cytochalasin B labeled low density microsomes $(300 \mu \mathrm{g})$ were incubated with $1 \mathrm{U}$ of endoglycosidase $F$ (New England Nuclear) in $0.1 \mathrm{ml}$ of $50 \mathrm{mM}$ phosphate buffer, $\mathrm{pH} 6.1$, containing $1 \%$ SDS, $1 \%$ Triton X-100, and $1 \%$ mercaptoethanol for $16 \mathrm{~h}$ at $37^{\circ} \mathrm{C}$. The protease inhibitors pepstatin $(5 \mu \mathrm{g} / \mathrm{ml})$, leupeptin $(5 \mu \mathrm{g} / \mathrm{ml})$ and aprotinin $(5 \mu \mathrm{g} / \mathrm{ml})$ were present.

After the incubation, samples were prepared for two-dimensional electrophoresis or immunoblotting as described above.

\section{Results}

Subcellular membrane characterization. Subcellular membrane fractions from isolated human omental and subcutaneous adipocytes were prepared and the purity of the fractions was determined by measuring the activity of specific marker enzymes in each fraction. Table I shows the specific activities of various marker enzymes characteristic of different subcellular organelles. Adenylate cyclase was used as the marker enzyme (21) of plasma membranes (PMs) and its specific activity was increased 16-fold over the homogenate. In addition, there was no appreciable contamination of this plasma membrane marker in either high density microsomes (HDMs) or low density microsomes (LDMs). The activity of cytochrome $c$ reductase, a marker enzyme of HDMs (22), was increased 49-fold in HDMs over the homogenate with minor activity in PMs and LDMs. UDP-Galactose $\mathrm{N}$-acetylglucosamine galactosyltransferase, a marker enzyme that identifies the Golgi apparatus (23), was most enriched in the LDMs with little contamination in PMs or HDMs.

Determination of glucose transporter number in subcellular membrane fractions derived from human omental and subcutaneous adipocytes. The number of glucose transporters in each
Table I. Distribution of Marker Enzyme Activities from Human Omental Adipocyte Subcellular Membrane Fractions

\begin{tabular}{|c|c|c|c|}
\hline & $\begin{array}{l}\text { NaF-stimulated } \\
\text { adenylate } \\
\text { cyclase }\end{array}$ & $\begin{array}{l}\text { NADH cytochrome } \\
\text { c reductase }\end{array}$ & $\begin{array}{l}\text { Galactosyl- } \\
\text { transferase }\end{array}$ \\
\hline & $\begin{array}{l}\text { pmol/min } \\
\text { per } \mathrm{mg}\end{array}$ & $\mu \mathrm{mol} / \mathrm{min}$ per $\mathrm{mg}$ & $\begin{array}{l}\text { nmol/2 } h \\
\text { per } m g\end{array}$ \\
\hline Homogenate & 4.0 & 0.046 & 1.9 \\
\hline PM & $65.0(16: 1)$ & 0.259 & 1.2 \\
\hline HDM & 2.0 & $2.27(49: 1)$ & 0.79 \\
\hline LDM & ND* & 0.069 & 4.87 (3: \\
\hline
\end{tabular}

Adenylate cyclase activity was used as a marker enzyme for plasma membranes, (21), NADH-cytochrome c reductase (22) and UDPgalactose: $N$-acetylglucosamine galactosyl-transferase (23) activity were used as marker enzymes for HDMs and LDMs, respectively. Numbers in parentheses represent the fold enrichment over homogenate for the marker enzyme corresponding to the indicated membrane fraction.

* ND, not detectable.

of the membrane fractions derived from basal and insulin stimulated cells was assessed by the D-glucose inhibitable cytochalasin B binding assay (15). As shown in Fig. 1, insulin caused the translocation of glucose transporters from the LDMs to the PMs in human omental adipocytes, which is consistent with the findings in rat adipocytes $(7,8,24)$ and other insulin sensitive tissues, e.g., rat diaphragm (25). Fig. 2 shows that the subcellular distribution and the effect of insulin on glucose transporter distributions was very similar in subcutaneous adipocytes. In both adipose tissues, PM glucose transporters increased two- to threefold upon exposure to insulin and there was a quantitatively similar decrease in LDM glucose transporters. Based on these findings, we performed all other experiments with membranes derived from omental adipocytes, since the needed amounts of membrane proteins were easier to generate from the more abundant omental adipose tissue.

Immunological detection and biochemical characterization of the human omental adipocyte glucose transporter. Fig. 3 shows

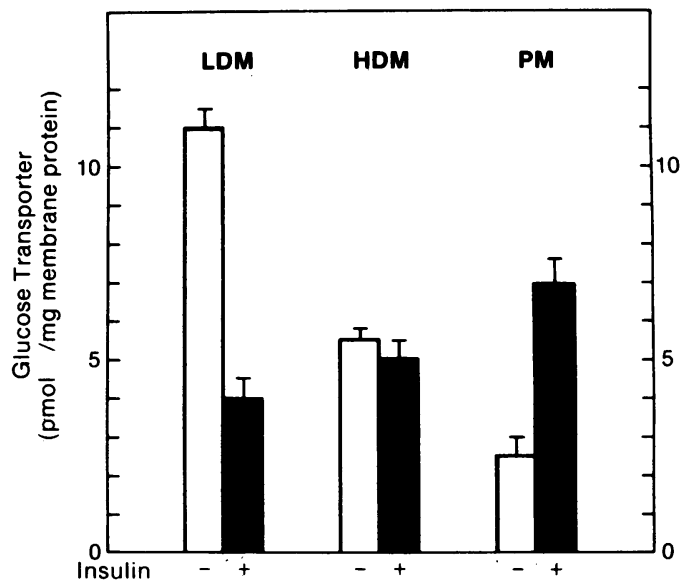

Figure 1. Distribution of glucose transporters in LDM, HDM and plasma membranes (PM) from human omental adipocytes incubated with and without insulin. Binding sites have been assessed by the $D$ glucose-inhibitable cytochalasin B binding assay (15). Data represent mean of three separate experiments \pm SEM. 


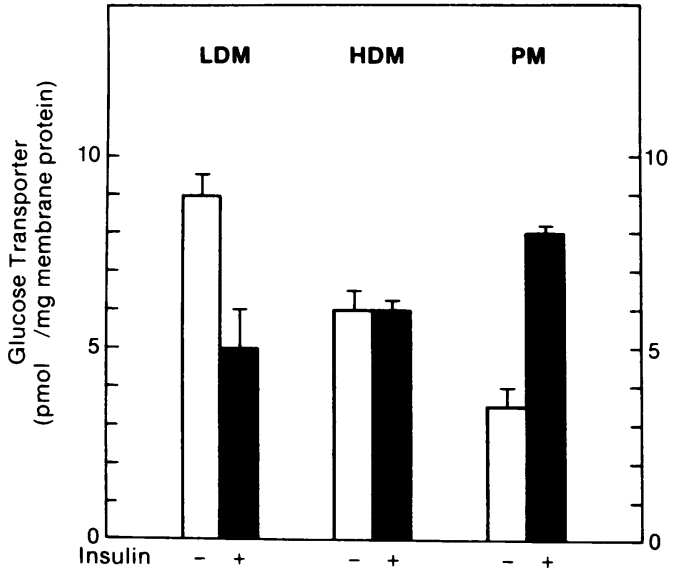

Figure 2. Distribution of glucose transporters in LDMs, HDMs, and PMs from human subcutaneous adipocytes incubated with and without insulin. Binding sites have been assessed by the D-glucose-inhibitable cytochalasin B binding assay (15). Data represent mean of three separate experiments \pm SEM.

the immunological detection of the human omental adipocyte glucose transporter in membrane subfractions derived from basal and insulin-stimulated cells. Membrane proteins (LDM: $100 \mu \mathrm{g}$; PMs: $20 \mu \mathrm{g}$ ) were subjected to SDS-PAGE (9\% resolving gels), blotted to nitrocellulose, and glucose transporters were detected using an antiserum raised against the purified erythrocyte glucose transporter (26). The results show that the human omental adipocyte transporter has an apparent molecular mass of $46 \mathrm{kD}$ on SDS-PAGE in all membrane species. In addition, insulin caused a decrease of carrier proteins in LDMs together with a concomitant increase in PMs. Therefore, insulin appeared to stimulate a translocation of glucose transporters from an intracellular pool to the plasma membrane, in confirmation of the findings from the cytochalasin B binding studies (Figs. 1 and 2). It should be noted that the relative intensity of the PM glucose transporter in Fig. 3 is less due to the smaller amount of protein $(20 \mu \mathrm{g})$ subjected to SDS-PAGE compared with LDMs (100 $\mu \mathrm{g})$.

To further biochemically characterize the human omental adipocyte glucose transporter, subcellular membrane fractions were covalently labeled with $\left[{ }^{3} \mathrm{H}\right]$ cytochalasin $\mathrm{B}$, and the radiolabeled membrane proteins in each of these fractions were analyzed by two-dimensional electrophoresis as described in Methods. The first phase of this modified two-dimensional pro-

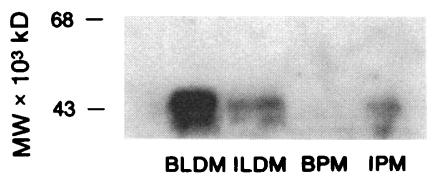

Figure 3. Immunological detection of the human omental adipocyte glucose transporter. Cells were incubated with and without insulin and subcellular membrane fractions-basal

low-density microsomes (BLDM), insulin low-density microsomes (ILDM), basal plasma membrane (BPM) and insulin plasma membrane (IPM)-were prepared as described in Methods. Membranes were analyzed by SDS-PAGE on $9 \%$ resolving gels, and transferred to nitrocellulose. The nitrocellulose blots were then incubated with antiserum raised against purified human erythrocyte glucose transporter, and the crossreacting proteins identified using ${ }^{125} \mathrm{I}$-protein $\mathrm{A}$ and autoradiography. Only the $35-68 \mathrm{kD}$ region of the autoradiogram is shown for clarity. $100 \mu \mathrm{g}$ of BLDM, ILDM and $20 \mu \mathrm{g}$ of plasma membranes (BPM, IPM) were used. tocol (10) involved SDS-PAGE. Fig. 4 shows a typical SDSPAGE profile on $\left[{ }^{3} \mathrm{H}\right]$ cytochalasin B labeled plasma membrane proteins derived from insulin-stimulated cells. It can be seen that the human omental adipocyte glucose transporter resolved on SDS-PAGE as a protein of molecular mass of 40-50 kD, as assessed by D-glucose-inhibitable $\left[{ }^{3} \mathrm{H}\right]$ cytochalasin $B$ radioactivity. SDS-PAGE profiles of $\left[{ }^{3} \mathrm{H}\right]$ cytochalasin B labeled LDMs and HDMs gave qualitatively similar results (data not shown).

Following SDS-PAGE, membrane proteins of molecular mass of 40-55 kD were excised from duplicate gels and electrophoretically eluted as described by Hunkapiller (17). As shown in Fig. 5, when these radiolabeled proteins eluted from basal LDMs (A) and basal PMs (B) were analyzed by isoelectric focusing, two major peaks of radioactivity focusing at pH 6.4 and 5.6 were discernible in the LDMs, but only one peak focusing at $\mathrm{pH} 5.6$ was observed in the PMs. Preincubation of these membranes with $500 \mathrm{mM}$ D-glucose reduced the labeling of these peaks by $60-80 \%$. This preferential inhibition of $\left[{ }^{3} \mathrm{H}\right]$ cytochalasin $\mathrm{B}$ labeling is consistent with the stereoselectivity of the glucose transporter for D-glucose $(27,28)$. Thus, these data strongly suggest the presence of at least two glucose transporter isoforms in LDMs but only one in PMs in human omental adipocytes. When $\left[{ }^{3} \mathrm{H}\right]$ cytochalasin B labeled proteins HDMs were subjected to the two-dimensional electrophoresis protocol, a different pattern was observed. As can be seen in Fig. 6, only the pH 6.4 glucose transporter isoform was detected in HDMs. Since HDMs are highly enriched in endoplasmic reticulum, the organelle involved in protein synthesis, these data suggested that the $\mathrm{pH} 6.4$ glucose transporter isoform may be the initial glucose transporter synthesized in adipocytes.

To test whether insulin had any effect on the structure or distribution of the glucose transporter isoforms described above, we incubated intact adipocytes with insulin and prepared LDMs and PMs from these cells. Those membranes were then photolabeled with $\left[{ }^{3} \mathrm{H}\right]$ cytochalasin $\mathrm{B}$ and analyzed by two-dimen-

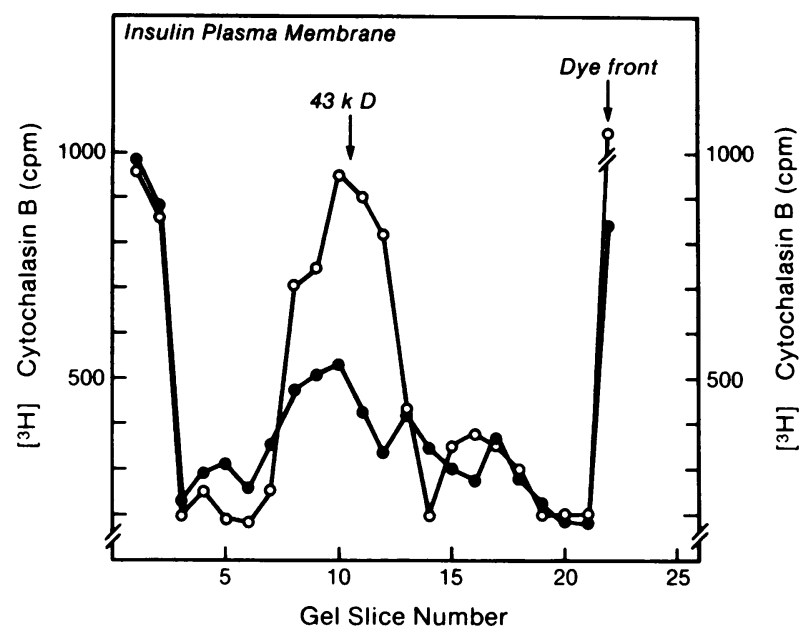

Figure 4. SDS-PAGE profile of $\left[{ }^{3} \mathrm{H}\right]$ cytochalasin B-labeled plasma membrane proteins preincubated in the presence of $D$ - or L-glucose. Plasma membranes from insulin-treated human omental adipocytes were incubated with $500 \mathrm{mM}$ D-glucose (solid circles) or L-glucose (open circles) before incubation with $\left[{ }^{3} \mathrm{H}\right]$ cytochalasin B for $10 \mathrm{~min}$ at $4^{\circ} \mathrm{C}$. The membranes were then irradiated with ultraviolet light at 254 $\mathrm{nm}$ for $5 \mathrm{~min}$ as described previously (10). Membrane protein (200$300 \mu \mathrm{g}$ ) was applied to $9 \%$ polyacrylamide gels and analyzed by SDSPAGE. Arrow indicates position of marker protein. 


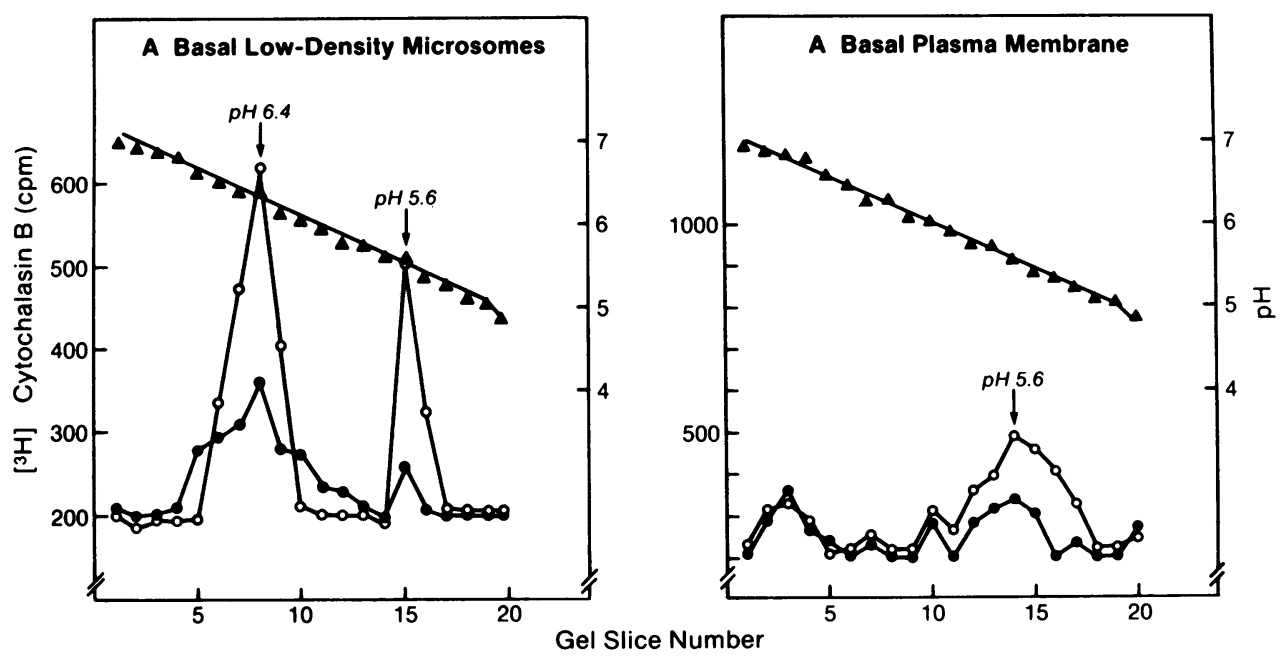

Figure 5. Isoelectric focusing of the SDS-PAGE purified, photoaffinitylabeled human omental adipocyte glucose transporter from basal LDMs and PMs. The $\left[{ }^{3} \mathrm{H}\right]$ cytochalasin B-labeled membrane proteins migrating at $40-55$ $\mathrm{kD}$ were excised from an SDSPAGE and after elution, were subjected to isoelectric focusing as described previously (10). Membranes were preincubated with $500 \mathrm{mM}$ Dglucose (solid circles) or L-glucose (open circles). Arrows indicate the isoelectric points $(\mathrm{pH})$ of the focused protein peaks. Experiments have been performed three times; the data represent a typical profile. sional electrophoresis. As shown in Fig. $7 A$ and $B$, when the 40-55-kD radiolabeled membrane proteins eluted from the SDSgel were analyzed by isoelectric focusing, two major peaks of radioactivity focusing at $\mathrm{pH} 6.4$ and 5.6 were found in the LDMs, with only one peak focusing at pH 5.6 seen in PMs. Since the pattern of glucose transporter isoforms was qualitatively identical in membranes derived from both basal and insulin stimulated adipocytes, insulin did not appear to structurally modify the glucose transporter in a way that could be detected by isoelectric focusing. However, although insulin did not influence charge heterogeneity, the hormone did have a differential effect on the subcellular distribution of glucose transporter isoforms. For example, insulin induced a marked increase in the $\mathrm{pH} 5.6$ isoform in the PM together with a concominant decrease in the pH 5.6 isoform in the LDMs. In contrast, insulin did not affect the pH 6.4 isoform in the LDMs (compare Figs. $5 A$ and $7 B$ ). Thus, averaging three separate experiments, insulin led to a $74 \%$ reduction in the $\mathrm{pH} 5.6$ glucose transporter isoform in LDMs with no effect on the pH 6.4 isoform, and a 2.2-fold increase in the pH 5.6 isoform in PMs. Insulin had no effect on the $\left[{ }^{3} \mathrm{H}\right]$ cytochalasin B-labeled glucose transporters in HDMs (data not shown). In aggregate, these results are quantitatively quite

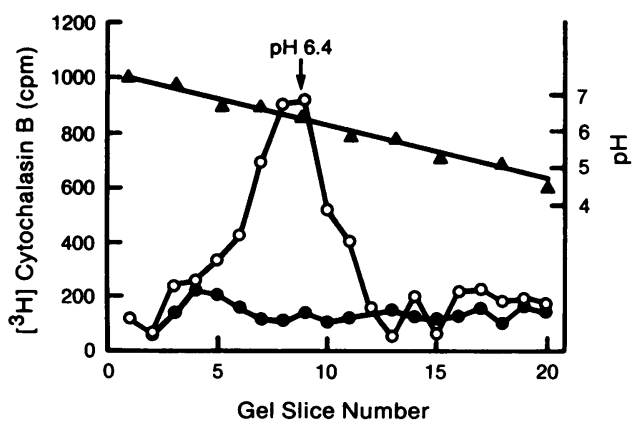

Figure 6. Isoelectric focusing of the SDS-PAGE purified, photoaffinitylabeled human omental adipocyte glucose transporter from basal HDMs. The $\left[{ }^{3} \mathrm{H}\right]$ cytochalasin B-labeled HDM proteins migrating at 40-55 kD were excised from an SDS-PAGE, and after elution were subjected to isoelectric focusing as described previously (10). Membranes were preincubated with $500 \mathrm{mM}$ D-glucose (solid circles) or Lglucose (open circles). Arrow indicates the isoelectric point $(\mathrm{pH})$ of the focused protein peak. comparable to the data obtained with the more conventional cytochalasin B binding assay as shown in Figs. 1 and 2.

The different charge properties of LDM glucose transporters could correspond to covalent modification of the glucose transporter such as differences in glycosylation. To assess this possibility we incubated photolabeled basal- and insulin LDMs with and without endoglycosidase $\mathrm{F}$ as described in Methods. Analysis of the membrane proteins by SDS-PAGE followed by immunological detection and autoradiography is seen in Fig. 8. Endoglycosidase $\mathrm{F}$ treatment resulted in a higher mobility of about half $(46 \%)$ of the original $46 \mathrm{kD}$-protein, now having a molecular mass of $38 \mathrm{kD}$, while the other half $(54 \%)$ still showed the original mass of $46 \mathrm{kD}$.

To determine the effects of endoglycosidase $\mathrm{F}$ on glucose transporter isoforms, these proteins were then resolved by isoelectric focusing. As shown in Fig. 9, treatment of $\left[{ }^{3} \mathrm{H}\right]$ cytochalasin B photolabeled basal $(A)$ and insulin $(B)$ LDMs with endoglycosidase $\mathrm{F}$ generated a new glucose transporter isoform focusing at $\mathrm{pH}$ 6.1. The $\mathrm{pH} 5.6$ transporter isoform was now almost entirely absent while the $\mathrm{pH} 6.4$ glucose transporter isoform was not sensitive to endoglycosidase $F$ treatment. Thus, endoglycosidase $\mathrm{F}$ induced an alkaline shift of the $\mathrm{pH} 5.6$ glucose transporter isoform consistent with the removal of charged $\mathrm{N}$ linked sugar residues from the carrier. Therefore, the charge heterogeneity observed in the two isoforms is at least partially due to differences in glycosylation. Endoglycosidase $F$ treatment of the membranes had no effect on the D-glucose-inhibitable $\left[{ }^{3} \mathrm{H}\right]$ cytochalasin B-labeled protein profile; for reasons of clarity these data are not shown in Fig. 9.

\section{Discussion}

The purpose of this study was to gain insight into the molecular mechanism of insulin action on glucose transport in human adipocytes. Using a modified two-dimensional electrophoresis approach (10) we have demonstrated both the biochemical and functional heterogeneity of glucose transporters in human omental adipocytes. In subcellular membrane fractions, there was charge heterogeneity of glucose transporter species in LDMs since we observed two isoforms focusing at pH 6.4 and $\mathrm{pH}$ 5.6. In contrast, only the pH 5.6 species was present in the PMs and only the pH 6.4 species was detected in the HDMs. We consider it extremely unlikely that glucose transporter isoforms could 


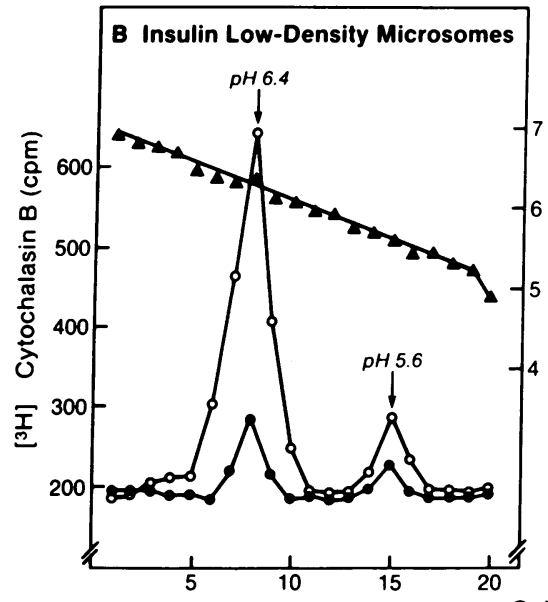

Gel Slice Number

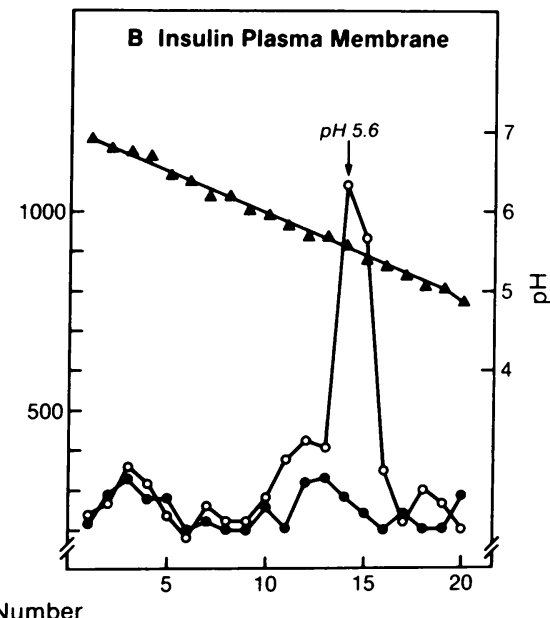

Figure 7. Isoelectric focusing of the SDSPAGE purified, photoaffinity-labeled human omental adipocyte glucose transporter from insulin LDMs and PMs. The $\left[{ }^{3} \mathrm{H}\right]$ cytochalasin B-labeled plasma membrane proteins migrating at $40-55 \mathrm{kD}$ were excised from an SDS-PAGE, and after elution, were subjected to isoelectric focusing as described previously (10). Membranes were preincubated with $500 \mathrm{mM}$ D-glucose (solid circles) or L-glucose (open circles). Arrows indicate the isoelectric points $(\mathrm{pH})$ of the focused peaks. Experiments have been performed three times; the data represent a typical profile.

have been generated by partial proteolysis of the molecule, since protease inhibitors (aprotinin, pepstatin, and leupeptin) were present during the entire procedure. Furthermore, partial proteolysis would have been expected to generate multiple forms of transporters in the HDM and PM fractions, where only one glucose transporter isoform was observed. The finding that insulin induced the translocation of only the $\mathrm{pH} 5.6$ glucose transporter isoform from the LDMs to the PMs in human adipocytes is of particular significance and is consistent with our recently reported results from rat adipocytes (10). Insulin did not cause redistribution of the pH 6.4 glucose transporter isoform. Obviously, the pH 5.6 species is the biologically active form of the transporter as far as uptake of glucose into the cell is concerned. Whether the pH 6.4 isoform is capable of transporting D-glucose remains to be determined.

The existence of glucose transporter heterogeneity in the LDMs is at least partially due to differences in glycosylation, since endoglycosidase $\mathrm{F}$ shifted the $\mathrm{pH} 5.6$ isoform to a more alkaline isoelectric point, now focusing at $\mathrm{pH} 6.1$, while the $\mathrm{pH}$ 6.4 glucose transporter isoform was not sensitive to endoglycosidase $\mathrm{F}$ treatment. This endoglycosidase $\mathrm{F}$-induced alkaline shift of the pH 5.6 glucose transporter indicates cleavage of charged asparagine-linked core oligosaccharides which also altered the mobility of transporters on SDS-PAGE. Using SDSPAGE and immunoblotting we found that glucose transporters initially resolved as a broad band with an apparent average molecular mass of $46 \mathrm{kD}$. After endoglycosidase F treatment two bands became evident. About half of the original $46-\mathrm{kD}$ proteins now displayed increased mobility $(38 \mathrm{kD})$ while the remainder

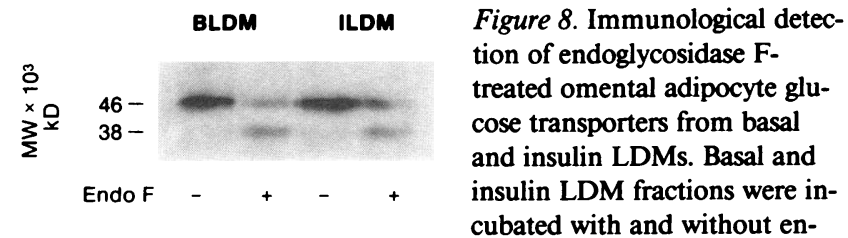

doglycosidase $\mathrm{F}$ as described in Methods. Membrane proteins were then analyzed by SDS-PAGE on $9 \%$ resolving gels, and transferred to nitrocellulose. Immunoblotting was as described in the legend for Fig. 3. Equal amounts of glucose transporter (picomoles per milligram membrane protein) were subjected to SDS-PAGE. Only the 30-55 kD region of the autoradiogram is shown for clarity. were unaffected by endoglycosidase $F$ treatment resolving at 46 $\mathrm{kD}$. These data suggest that both intracellular glucose transporter isoforms are proteins with an apparent average molecular mass of $46 \mathrm{kD}$ distinguishable only on isoelectric focusing. The differences in mobility of transporter proteins following endoglycosidase $\mathbf{R}$ treatment of LDMs could represent heterogeneity for structural differences other than glycosylation or differential susceptibility of transporter species to the enzyme.

Taken together with the observation that endoglycosidase $F$ treatment results in an alkaline shift of the pH 5.6 glucose transporter isoform to $\mathrm{pH} 6.1$, one could speculate that the endoglycosidase F-generated $38-\mathrm{kD}$ protein is the deglycosylated $\mathrm{pH} 5.6$ glucose transporter isoform, now having an isoelectric point of $\mathrm{pH}$ 6.1. The pH 6.4 glucose transporter isoform may represent an immature glucose transporter species that is not endoglycosidase $F$ sensitive. It is not clear whether the endoglycosidase $F$ insensitivity is due to inaccessibility of $\mathrm{N}$-linked core oligosaccharides to the enzyme or due to other structural features of this isoform. It should be noted that the $\mathrm{pH} 6.4$ isoform in untreated membranes cannot be simply a naturally occurring deglycosylated form of the transporter because its SDS-PAGE mobility was $46 \mathrm{kD}$, not $38 \mathrm{kD}$. Similarly, after endoglycosidase $\mathrm{F}$ treatment of LDMs, the residual $46 \mathrm{kD}$ species is unlikely to be enzyme resistant simply due to lack of oligosaccharide side chains, since its mobility is not in the $38-41-\mathrm{kD}$ range reported for the deglycosylated form of the glucose transporter $(29,30)$. In this regard, Haspel et al. $(29,30)$ and Mueckler et al. (31) have shown that the deglycosylated form of the human transporter is $38-41 \mathrm{kD}$, whereas the fully mature transporter has mobility of $55 \mathrm{kD}$. In the current study, we are in full agreement with the molecular mass of the deglycosylated transporter, but we found that the mature human adipocyte glucose transporter has an average mobility of $46 \mathrm{kD}$. The protein we have identified is certainly the glucose transporter since it binds cytochalasin B in a D-glucose-sensitive manner, is readily detected by anti-glucose transporter antibodies, and translocates from the LDM to PM fractions upon insulin stimulation. These differences in apparent molecular mass may relate to differences in SDS-PAGE systems for assessing the relative mobility of glycoproteins.

An additional, new finding in this study which supports the concept that the $\mathrm{pH} 6.4$ isoform is an immature glucose transport species, relates to the isoelectric focusing pattern noted in the HDMs. Thus, in HDMs (an intracellular membrane compart- 

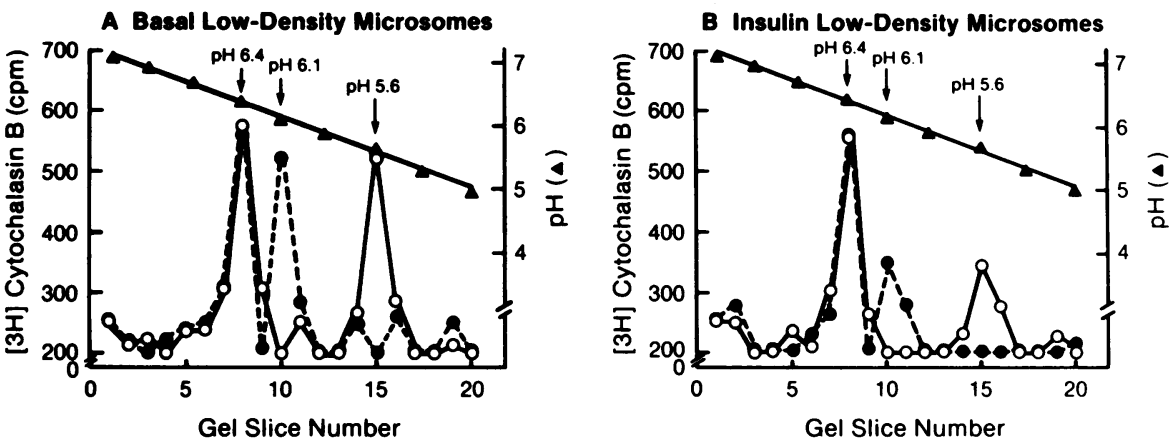

Figure 9. Isoelectric focusing of the SDSPAGE purified, photoaffinity-labeled human omental adipocyte glucose transporter from basal and insulin LDMs with and without endoglycosidase $F$ treatment. The $\left[{ }^{3} \mathrm{H}\right]$ cytochalasin B-labeled basal (A) and insulin LDM fractions (B) were incubated with (solid circles) and without (open circles) endoglycosidase $\mathrm{F}$ as described in Methods. Membrane fractions were analyzed by SDS-PAGE and proteins migrating at $30-55 \mathrm{kD}$ were excised from the gel, and after elution were subjected to isoelectric focusing as described previously (10). Arrows indicate the isoelectric points $(\mathrm{pH})$ of the focused peaks. ment enriched in endoplasmic reticulum), only the pH 6.4 glucose transporter isoform was detected. Since endoplasmic reticulum is the cellular organelle responsible for protein synthesis, we suggest from these data that, in human adipocytes, the glucose transporter is initially synthesized in HDMs as protein with an isoelectric point of $\mathrm{pH}$ 6.4. This newly synthesized protein is then posttranslationally modified in the Golgi apparatus (enriched in LDMs) by terminally capping with charged sugar residues, changing its isoelectric point to $\mathrm{pH}$ 5.6. This would account for the presence of both pH 6.4 and 5.6 isoforms in the LDMs. The pH 5.6 glucose transporter isoform would then represent the mature protein capable of transporting glucose across the plasma membrane and sensitive to insulin-induced recruitment from the LDM to PM fraction.

In summary, we have shown that in human adipocytes, glucose transporters exist as heterogeneous species in subcellular membrane fractions. These species (pH 6.4 and 5.6 isoforms) exist in LDMs, but only the pH 5.6 isoform can be translocated to plasma membranes by insulin. It is suggested that the $\mathrm{pH} 6.4$ isoform is an immature transporter species synthesized in the HDMs, migrating to the LDM fraction where it is converted to the 5.6 species, which is the transporter target for insulin-induced recruitment to PMs. It will be of interest to determine whether qualitative or quantitative alterations in these glucose transporter species or in their distribution within subcellular membrane fractions exists in human insulin-resistant states.

\section{Acknowledgments}

We would like to thank Drs. Soraya Nagshineh and Suzanne Beckner for performing the adenylate cyclase assay, and Drs. Sam Cushman and Ian Simpson for their generous gift of glucose transporter antisera. We wish to thank Linda McCaren for her excellent technical assistance and Elizabeth Martinez and Cleon Tate for their expert secretarial assistance in the preparation of this manuscript.

Stephan Matthaei is a recipient of a grant from the Deutsche Forschungsgemeinschaft. W. Timothy Garvey is a recipient of a Pfizer Postdoctoral Fellowship Award. This work was supported by research grants AM-33651 and AM-33649 from the National Institutes of Health.

\section{References}

1. Olefsky, J. M. 1980. Insulin resistance and insulin action. An in vitro and in vivo perspective. Diabetes. 30:148-162.

2. Lockwood, D. H., and J. M. Amatruda. 1983. Cellular alterations responsible for insulin resistance in obesity and Type II diabetes mellitus. Am. J. Med. 75(Suppl. 5B):23-31.

3. Kolterman, O. G., R. S. Gray, J. Griffin, P. Burstein, I. Insel, J. A. Scarlett, and J. M. Olefsky. 1981. Receptor and post-receptor defects contribute to the insulin resistance in non-insulin dependent diabetes mellitus. J. Clin. Invest. 68:957-969.

4. Pedersen, O., E. Hjolland, and N. S. Sorensen. 1982. Insulin receptor binding and insulin action in human and fat cells: Effects of obesity and fasting. Metab. Clin. Exp. 31:884-895.

5. Ciaraldi, T. P., O. G. Kolterman, J. A. Scarlett, M. Kao, and J. M. Olefsky. 1982. Role of glucose transport in the postreceptor defect of non-insulin-dependent diabetes mellitus. Diabetes. 31:1016-1022.

6. Armoni, M., R. Rafaeloff, A. Bavzilai, and E. Karnieli. 1985. A possible mechanism of insulin resistance in human adipose cells: depletion of the intracellular pool of glucose transporters. Diabetes. 34(Suppl. 1): 82A, 328. (Abstr.)

7. Cushman, S. W., and L. J. Wardzala. 1980. Potential mechanism of insulin action on glucose transport in the isolated rat adipose cell. $J$. Biol. Chem. 255:4758-4762.

8. Suzuki, K., and T. Kono. 1980. Evidence that insulin causes translocation of glucose transport activity to the plasma membrane from an intracellular storage site. Proc. Natl. Acad. Sci. USA. 77:2542-2545.

9. Kobayashi, M., J. M. Olefsky, J. Elders, M. E. Mako, B. D. Given, H. K. Schedwie, R. H. Fiser, R. L. Hintz, J. A. Horner, and A. H. Rubenstein. 1978. Insulin resistance due to a defect distal to the insulin receptor: demonstration in a patient with leprechaunism. Proc. Natl. Acad. Sci. USA. 75:3469-3473.

10. Horuk, R., S. Matthaei, J. M. Olefsky, D. L. Baly, S. W. Cushman, and I. A. Simpson. 1986. Biochemical and functional heterogeneity of rat adipocyte glucose transporters. J. Biol. Chem. 261:1823-1828.

11. Rodbell, M. 1964. Metabolism of isolated fat cells. J. Biol. Chem. 239:375-380.

12. Karnieli, E., M. J. Zarnowski, P. J. Hissin, I. A. Simpson, L. B. Salans, and S. W. Cushman. 1981. Insulin-stimulated translocation of glucose transport systems in the isolated rat adipose cell. J. Biol. Chem. 256:4772-4777.

13. Lowry, O. H., N. J. Rosebrough, A. L. Farr, and R. F. Randall. 1951. Protein measurement with the Folin phenol reagent. J. Biol. Chem. 193:265-275.

14. Peterson, G. L. 1977. A simplification of the protein assay method of Lowry et al which is more generally applicable. Anal. Biochem. 83: 346-356.

15. Wardzala, L. J., S. W. Cushman, and L. B. Salans. 1978. Insulinstimulated translocation of glucose transport systems in the isolated rat adipose cell. J. Biol. Chem. 253:8002-8005.

16. Beeley, J. A., S. M. Stevenson, and J. G. Beeley. 1972. Polyacrylamide gel isoelectric focusing of proteins: determination of isoelectric points using an antimony electrode. Biochim. Biophys. Acta. 285:293300.

17. Hunkapiller, M. W., E. Lujan, F. Ostrander, and L. E. Hood. 
1983. Isolation of microgram quantities of proteins from polyacrylamide gels for amino acid sequence analysis. Methods Enzymol. 91:227-235.

18. Horuk, R., and D. E. Wright. 1983. Partial purification and characterization of the glucagon receptor. FEBS (Fed. Eur. Biochem. Soc.) Lett. 155:213-217.

19. Towbin, H., T. Staehelin, and J. Gordon. 1979. Electrophoretic transfer of proteins from polyacryalmid gels to nitrocellulose sheets: procedure and some applications. Proc. Natl. Acad. Sci. USA. 76:43504354.

20. Wheeler, T. J., I. A. Simpson, D. C. Sogin, P. C. Hinkle, and S. W. Cushman. 1982. Detection of the rat adipocyte glucose transporter with an antibody against the human red cell glucose transporter. Biochem. Biophys. Res. Commun. 105:89-95.

21. Salomon, Y., C. Landos, and M. Rodbell. 1974. A highly sensitive adenylate cyclase assay. Anal. Biochem. 58:541-548.

22. Dallner, G., P. Sickevitz, and G. E. Palade. 1966. Biogenesis of endoplasmic reticulum membranes. J. Cell Biol. 30:97-117.

23. Fleisher, B. 1974. Isolation and characterization of Golgi apparatus and membranes from rat liver. Methods Enzymol. 31:180-191.

24. Oka, Y., and M. P. Czech. 1984. Photoaffinity labeling of insulinsensitive hexose transporter in intact rat adipocytes. J. Biol. Chem. 259: 8125-8133.
25. Wardzala, L. J., and B. Jeanrenaud. 1981. Potential mechanism of insulin action on glucose transport in the isolated rat diaphragm. $J$. Biol. Chem. 256:7090-7093.

26. Baldwin, S. A., and G. E. Lienhard. 1980. Immunlogical identification of the human erythrocyte monosaccharide transporter. Biochem. Biophys. Res. Commun. 94:1401-1408.

27. LeFevre, P. G. 1961. Sugar transport in the red blood cell: structure-activity relationship in substrates and antagonists. Pharmacol. Rev. 13:39-70.

28. Pessin, J. E., L. G. Tillotson, K. Yamada, W. Gitomer, G. Carter$\mathrm{Su}, \mathrm{R}$. Mora, K. J. Isselbacher, and M. P. Czech. 1982. Identification of the stereospecific hexose transporter from starved and fed chicken embryo fibroblasts. Proc. Natl. Acad. Sci. USA. 79:2286-2290.

29. Haspel, H. C., M. J. Birnbaum, E. W. Wilk, and O. M. Rosen. 1985. Biosynthetic precursors and in vitro translation products of the glucose transporter of human hepatocarcinoma cells, human fibroblasts, and murine preadipocytes. J. Biol. Chem. 260:7219-7225.

30. Haspel, H. C., E. W. Wilk, M. J. Birnbaum, S. W. Cushman, and O. R. Rosen. 1986. Glucose deprivation and hexose transporter polypeptides of murine fibroblasts. J. Biol. Chem. 261:6778-6789.

31. Mueckler, M., and H. Lodish. 1986. The human glucose transporter can insert posttranslationally into microsomes. Cell. 44:629-637. 